\title{
O “OUTRO" DA FILOSOFIA DA EDUCAÇÃO DE ADORNO: A PSICANÁLISE
}

Pedro Rogério Sousa da Silva ${ }^{1}$

\section{Resumo:}

O presente texto busca investigar a presença do "outro" na filosofia de Adorno, quer dizer, visa-se elucidar que este "outro" corresponde ao elemento da teoria psicanalítica, pois tal teoria fora tradicionalmente refutada pela filosofia moderna. Nestes termos, mostraremos que duas correntes de pensamentos contribuíram significativamente para essa refutação, são elas: a transcendental kantiana e a filosófica-economicista marxiana. Para tanto, faremos um recorte dos textos de Adorno que trata da psicanálise, em seguida, procuraremos encontrar similitudes e divergências à educação.

Palavras-chave: Adorno; Psicanálise; Kant; Marx; educação.

\begin{abstract}
:
This paper investigates the presence of "other" in Adorno's philosophy, that is, it is intended to clarify that this "other" is the element of psychoanalytic theory because that theory had traditionally been refuted by modern philosophy. Accordingly, we show that two currents of thought have contributed significantly to this refutation, they are: Kant and the transcendental-philosophical Marxist economist. To this end, we will cut texts dealing with Adorno's psychoanalysis, then try to find similarities and differences to education.
\end{abstract}

Keywords: Adorno, Psychoanalysis, Kant, Marx.

Somando-se à grande influência marxista a fim de melhor compreender a problemática do capitalismo nos meandros do século XX e suas consequências deletérias para a vida humana, procuramos acrescentar ainda o interesse pela Psicanálise freudiana para uma compreensão mais densa para a subjetividade, no quadro interno dos integrantes do Instituto de Pesquisa Social, sobretudo os que pertenceram à primeira geração deste Instituto. Assim, em especial, Adorno passa a inaugurar e a reconhecer o espectro da Psicologia e/ou Psicanálise como uma fonte de inspiração da Teoria Social e da Teoria do Conhecimento em um território que tradicionalmente fora colonizado e dominado pelos grandes filósofos racionalistas. Nestes termos, podemos dizer que a

\footnotetext{
${ }^{1}$ Doutorando em Educação pela Universidade Federal do Ceará (UFC). Bolsista da CAPES/DS, vinculado ao Eixo Filosofia, Política e Educação.
} 
integração do pensamento de Freud em tal Instituto, segundo o filósofo Sérgio Paulo Rouanet, implica um elo entre a teoria freudiana do inconsciente (e da sexualidade) em "parceria" com a dimensão filosófico-econômica de Marx, mas ressaltando que esse entrelaçamento não aconteceu de modo aleatório, pois dois acontecimentos históricos do começo do século passado, tais como a Revolução Bolchevista de 1917 e a tomada do poder de Adolf Hitler na Alemanha, foram significativas para capturar de vez tal elo (ROUANET, 1989).

Ainda porque, como sabemos, a Psicanálise, nos tempos de Lenin ou no início de tal revolução, esteve sempre em contato com a teoria crítica marxista, havendo traduções da obra de Freud para a língua russa, surgindo consultórios de clínica psicanalítica, disciplinas de Psicanálise nas universidades soviéticas e durante a gestão “[...] de Bela Kun, na Hungria, em 1919, Sándor Ferenczi foi convidado para criar uma disciplina de psicanálise na Universidade de Budapeste" (ROUANET, 1989, p. 15). Não obstante, nem tudo na vida é eterno, pois ocorreu, em dado momento, um rompimento destas correntes: a psicanalítica e a marxista. O motivo de tal rompimento iniciou-se com a morte de Lenin. Com esse acontecimento, o(s) discípulos que o sucederam não continuaram com o mesmo legado deixado pelo mestre, ou seja, o interesse pela parceria com tais correntes de pensamento europeias. Nesta circunstância, a Psicanálise, em especial a de linha freudiana, foi perdendo espaço, acusada pelos marxistas como algo que estaria vinculado a uma espécie de 'charlatanice' por alguns críticos mais severos, a saber, aqueles que organizavam a Revista Unter dem Banner, mas também por outros opositores que faziam a seguinte indagação: a Psicanálise é realmente ciência? Ou, ainda melhor, caso a Psicanálise fosse considerada ciência como se classificaria: como ciência da humanidade ou da natureza? (ROUANET, 1989).

Depois de todas essas acusações infrutíferas, não restou outro caminho ao legado teórico de Freud a não ser o seu desaparecimento quase que totalitário da esfera soviética por um tempo significativo, para dar lugar a outros pensamentos considerados adequados e condizentes com a ordem vigente da época, como os propostos por Ivan Pavlov e do marxismo "mecanicista-positivista". A propósito do marxismo mecanicista, podemos dizer que esta não foi apenas uma simples teoria, mas uma grande ideologia que se implantou no Estado da URSS, tanto que fora para muitas pessoas uma religião. Seguindo essa onda de ataques à Psicologia, esta, nos tempos de Adorno, se destinou principalmente à Psicanálise. Entretanto, vale dizer que não fora apenas o legado dos sucessores de Lenin que fizerem severas críticas à Psicanálise, haja vista que o 
problema dos estudos psicológicos esteve sempre presente na esfera filosófica, em especial na História da Filosofia moderna como algo que deveria ser execrado. Ou seja, este tipo de conhecimento deveria ser entendido como uma área do conhecimento de segunda categoria que, aliás, teria de ser refutada de tal ambiente (ROUANET, 1989).

Conforme Vladimir Safatle, professor de Filosofia da Universidade de São Paulo (USP), isto tem origem, certamente, no discurso que a partir de Kant, sobretudo de suas três críticas $^{2}$, tais como Crítica da razão pura (1781), Crítica da razão prática (1788) e Crítica do juízo (1790), ganhou uma interpretação destinada a denegrir todo pensamento filosófico que se aproximasse da temática psicológica, acusando-a de ser um modo de proceder que dissimulava a circulação da razão, como se fosse algo composto de elementos que não ofereciam nenhum pressuposto de validade transcendental para o sujeito do conhecimento, a saber, aquele que conhece e constitui o conhecimento. A parir dessa abordagem crítica, Safatle nos provoca a refletir sobre estes questionamentos em torno do psicologismo, alertando para a possibilidade de que:

\begin{abstract}
Por trás do psicologismo, pulse a compreensão de que nada que aspira validade incondicional para nós é indissociável de sua gênese. Como se questões de validade e de gênese não pudessem em absoluto ser separadas. Digamos que foi isto que um "psicólogo", Sigmund Freud, compreendeu ao se perguntar sobre a gênese empírica dos sentimentos morais a partir dos conflitos familiares. Tratava-se de mostrar como o sentido daquilo que aspira validade transcendental no domínio da razão prática é indissociável da determinação de sua gênese. Uma determinação que acaba por fornecer as coordenadas gerais para a crítica (SAFATLE, 2010, p. 45-46).
\end{abstract}

Nesta direção, os pesquisadores frankfurtianos concretizaram seus pressupostos, lançando mão do próprio espectro do psicologismo, dando a este um valor positivo. Podemos, entretanto, nos referir à forma do próprio tratamento de Adorno, à Psicanálise (psychanalyse), em especial a de linhagem freudiana, que é um tipo de saber esclarecedor ou, melhor ainda, um ramo do conhecimento que adentra o psiquismo humano para entendê-lo. Não obstante, lembremo-nos de que vale a pena observar, no que diz respeito a Adorno, que ele se diferencia, neste ponto, sobretudo, de Erich

\footnotetext{
${ }^{2}$ As três críticas citadas representam uma das vertentes do pensamento kantiano. Ou seja, segundo Kastrup, a Filosofia de Kant foi seguida e amplamente desenvolvida nas interpretações de diversos autores, entre os quais destacam-se as de Adorno e de Foucault, bem como entendida por duas visões: a analítica da verdade e a ontologia do presente. Em suma, a primeira diz respeito a um pensamento que se volta para questões de legitimidade do saber, quer dizer, daquilo que valida o conhecimento e mostra como o (s) postulado(s) do conhecimento científico acontece(m). Já a segunda faz alusão à pergunta Was ist Aufklärung?, de Adorno, a qual utilizamos no presente trabalho de modo positivo. Ou seja, Adorno vai além de uma simples visão que se preocuparia tão-somente com as questões de validade do conhecimento, por estar atento as situações individuais, como, por exemplo, a autonomia do pensamento, mas também por refletir em torno das questões do coletivo, como é caso atual em sua época, do iluminismo (KASTRUP, 1999).
} 
Fromm e de Jürgen Habermas, porque, de maneira alguma, pretendia fazer algum tipo de enveredação com a clínica psicanalítica. Como se sabe, Adorno conhecia muito bem a Psicanálise e sabia do perigo que estava correndo caso fosse utilizar sua filosofia de modo clínico, uma vez que não aceitava os rigores de uma terapia para a "fortificação do eu", haja vista que:

[...] o Eu como representante do princípio de realidade no interior do sistema psíquico é, sobretudo, a instância responsável pelas resistências e pelos processos de recalcamento de exigências pulsionais. Neste sentido, fortalecêlo seria uma operação indissociável da perpetuação de uma forma de alienação (SAFATLE, 2008, p. 50-51).

Por outro lado, Adorno talvez não abra mão totalmente da clínica psicanalítica, por acreditar que ela pode atuar como um importante instrumento de (re) orientação dos sujeitos ante as patologias psicossociais que ocorreram durante as duas grandes guerras mundiais e que poderão a qualquer momento suceder novamente. Para tanto, o mesmo autor toma como axioma primordial o legado freudiano de que o período de formação do inconsciente aconteceria entre o primeiro ao sétimo ano de vida, ou seja, Adorno concorda com Freud na ideia de que, nesse período da infância, se constituiria a formação do Eu e da personalidade com seus significados e traços, como recalques, sentimento de culpa, ressentimentos, traumas, bloqueios, dentre outras marcas (ADORNO, 1995).

Por estes termos, o Filósofo frankfurtiano acredita, então, que o mal-estar na cultura (o mal-estar na condição humana) ou a causa de inúmeros problemas (e sintomas) psíquicos que se apresentam na fase adulta estariam relacionados a uma deficiência socioafetiva dos indivíduos. Disse o mesmo autor:

[...] na medida em que conforme os ensinamentos da 'psicanálise' e da psicologia profunda, todo caráter, inclusive daqueles que mais tarde praticam crimes, forma-se na primeira infância, a educação deve ter por objetivo evitar a repetição precisa que se encontra na primeira infância (ADORNO, 1995, p. 122).

Desse modo, pode-se inquirir: o que quer Adorno? Grosso modo, ele quer utilizar a Psicanálise de tal modo que ela possa funcionar como base teórica de enorme contribuição à famosa teoria crítica, para se entender melhor os défices socioculturais, bem como os transtornos psíquicos do coletivo e dos indivíduos, no caso de exemplificação, a personalidade autoritária, desembocadora da catástrofe por excelência, a saber, Auschwitz.

Com efeito, Joel Whitebook, psicanalista e também estudioso da teoria crítica, aponta que: 


\begin{abstract}
Além de Hegel, Marx e Weber, Freud tornou-se uma das pedras fundamentais sobre a qual o programa de interdisciplinaridade para uma teoria crítica da sociedade, foi construído. Observou-se várias vezes que os teóricos críticos voltaram-se para a psicanálise para corrigir uma deficiência na teoria marxista, a saber, sua redução do reino psicológico a fatores socioeconômicos (WHITEBOOK, 2008, p. 105).
\end{abstract}

Seguindo essas pegadas, verificamos que a aproximação dos filósofos frankfurtianos, sobretudo de Adorno, com a teoria psicanalítica foi muito mais além do que uma profunda influência teórica, chegando ao ponto de uma extrema intimidade, quer dizer, de sua convivência com a teoria crítica no mesmo espaço de trabalho. Em outras palavras, “O Instituto de Pesquisa Social e o Instituto Psicanalítico de Frankfurt dividiam o mesmo edifício e davam aulas nas mesmas salas" (WHITEBOOK, 2008, p. 106). Por fim, podemos acrescentar que o diretor do Instituto de Pesquisa Social, o filósofo Max Horkheimer, era membro do Instituto de Psicanálise, no qual participara também de seu grupo administrativo.

Ainda sobre essa imbricação, podemos dizer, primeiramente, que toda parceria tem suas limitações e pode chegar ao seu fim. E foi isso que acontecera com Horkheimer. Após voltar (junto com Adorno) dos Estados Unidos, período em que terminou a Segunda Guerra Mundial, Horkheimer deixou de enveredar, de uma maneira ou de outra, pelo espectro da Psicanálise, passando a se dedicar a outros objetos de pesquisa (RUSH, 2008).

Atitude próxima a essa ocorreu nos meados da década de 1970, com a Filosofia de Habermas, que ao aceitar inicialmente o campo da Psicanálise, demonstrou um profundo interesse de estudá-la de modo sistemático e metodológico, acreditando que o método psicanalítico poderia ser um recurso fundante para a sua teoria crítica. No decorrer de sua maturidade intelectual, porém, passou a criticá-la e a abandoná-la, seguindo outro percurso, que se dizia ser totalmente diferente desse e ligado com as seguintes questões teóricas: a) a Filosofia do Direito - de proximidades com a Teoria do Liberalismo; b) e a sua famosa Teoria da Comunicação. Sobre esta última questão e conforme a interpretação de Whitebook a respeito de Habermas, a Filosofia habermasiana conceberia o estudo psicanalítico como um saber voltado meramente para uma Filosofia da Comunicação, fato que contribui para sua criação da Teoria da Ação Comunicativa, mas também para seu distanciamento dos postulados freudianos, no qual a Psicanálise se tornou desnecessária (WHITEBOOK, 2008).

Habermas com sua visão progressista-racionalista da Modernidade (em suma, com sua descrença do socialismo e sua cautela com as questões de esquerda, que 
levaram o autor a defender os pressupostos da democracia liberal), em uma frontal contraposição a Adorno, utilizaria em sua Filosofia um modo de conceber o Eu psicanalítico como positivo. Assim sendo, tal modo de filosofar (por meio de sua pragmática filosofia da ação comunicativa) passaria agora a fazer um uso constante de outro campo do conhecimento, o da Psicologia Cognitiva, de Lawrence Kohlberg e de Jean Piaget. De modo distinto do pensamento habermasiano, porém, Adorno deu continuidade aos estudos psicanalíticos, mas de uma perspectiva negativa que levaria ao encontro de sua Dialética Negativa. A propósito, cabe observar que, já na obra Dialética do Esclarecimento (Dialektik der Aufklärung), Adorno nos mostra um uso bastante significativo de diversos conceitos da teoria psicanalítica, como, aliás, acontece em outros trabalhos - como no texto Personalidade Autoritária (Autoritharian Personsality) e no seu último curso, Introdução à Sociologia (Einleitung in die Soziologie), de 1968, em que ministrou aulas sobre Freud e Jung. Neste curso de cunho sociológico, Adorno trabalhou temas relacionados à delimitação da Sociologia com outras disciplinas, destacando inclusive o seu interesse de, no ano posterior, ministrar aulas a respeito de uma corrente de pensamento que se tornara uma espécie de fenômeno nos anos de 1960 na França, o estruturalismo. Ele tinha como meta abordar os estudos antropológicos de Claude LéviStrauss e da psicanálise de Jacques Lacan (ADORNO, 2008). Disse o filósofo frankfurtiano:

\footnotetext{
Espero poder oferecer um seminário sobre o estruturalismo - esse estruturalismo toma seu material essencialmente e por motivos plenamente justicáveis pelos temas de sua formação teórica, em primeiro lugar da antropologia e, além disso, de orientações específicas da pesquisa da linguagem, em especial a fonológica, tal como representada em Viena sobretudo por Trubetzkoi (ADORNO, 2008, p. 250).
}

Adorno, contudo, não pôde ministrar o curso sobre o estruturalismo, “[...] porque chegou a falecer em 1969” (ASSOUN, 1991, p. 35). E, no que tange à Fonologia e à Linguística em geral, Lacan, autor já citado por Adorno, aborda em seu trabalho psicanalítico questões desse gênero. Segundo a interpretação de Žižek, o Psicanalista francês realiza certo retorno a Freud, isto é, mostra, com o apoio da linguagem, da teoria matemática e de inúmeros conceitos filosóficos de autores da Filosofia moderna, alguns elementos não explicitados na teoria freudiana, pois a tese lacaniana consiste em mostrar que o Psicanalista vienense "[...] não estava ciente da noção de fala implicada por sua própria teoria e prática, e que só podemos desenvolver essa noção se nos referirmos à linguística saussuriana, à teoria dos atos de fala e à dialética hegeliana do reconhecimento" (ŽIŽEK, 2006, p. 9-10). 
Voltando ao Filósofo frankfurtiano, vale a pena afirmar que ele só tomou conhecimento de Jacques Lacan no fim de sua vida; no entanto, de acordo com Vladimir Safatle (2008), “[...] podemos imaginar que a teoria lacaniana do Eu como princípio de organização psíquica constituída a partir da introjeção da imagem do outro e da posterior denegação de tal processo poderia servir a Adorno" (ADORNO, 2008, p. 53). Tanto que o filósofo e psicanalista alemão Whitebook promove de maneira didática e sistemática aproximações entre ambos os pensadores, mais especificamente sobre a concepção do Eu, como pode ser visto de três ângulos:

1) A unidade do Eu é rígida, compulsiva e coercitiva; 2) O Eu é uma estrutura
narcísica (paranoica) na medida em que ele só pode apreender o objeto através
de sua própria reflexão (ou projeção), ; 3) O Eu rigidamente integrado é
profundamente implicado com a vontade de poder e com a dominação da
natureza (WHITEBOOK, 1995 apud SAFATLE, 2008, p. 133).

Tais aproximações são de suma importância para os estudiosos que relacionaram a Teoria Psicanalítica com a Filosofia, apesar de elas não passarem de uma analogia que poderia ser amplamente explorada pelos pensadores europeus mencionados: o Psicanalista parisiense e o Filósofo frankfurtiano. Não obstante, o que pode ser considerado como prático e importante a este contexto é que a perspectiva adorniana encontra uma legitimação suplementar nas teorias da constituição da função do Eu do psicanalista francês Jacques Lacan (SAFATLE, 2008, p. 53).

Vale a pena lembrar, ao menos neste ponto, que o certo é que para Adorno estabelecer sua interpretação psicanalítica relacionada à Teoria Crítica, teve ele que se apoiar mesmo no legado freudiano, como, por exemplo, em suas concepções de sujeito e de ontogênese, uma vez que criticava o modo de contenção majoritário da identidade como algo vinculado à noção do EU. Por fim, lembramos que Adorno, desde cedo, já se apropriava das noções freudianas em seus textos. Isto acontecera precocemente, já em sua tese de habilitação (habilitationsschrift), de 1928, para o cargo de professor da Universidade de Frankfurt, intitulada "O conceito de inconsciente na teoria transcendental da mente". Para a infelicidade do Filósofo frankfurtiano, no entanto, sua tese não fora aceita pelo seu orientador, o filósofo Hans Cornelius (ZUIN; PUCCI; RAMOS-DEOLIVEIRA, 2008, p. 26).

Adorno, no entanto, não desistiu de realizar sua habilitação para professor de Filosofia na Universidade de Frankfurt, tanto que tentou novamente o concurso, mas agora com outro orientador, o teólogo Paul Tillich, e com outra tese que fora intitulada de Kierkergaard: Konstruktion des Ästhetischen (Kierkergaard: construção do estético), 
sendo desta vez aprovada naquela Universidade em 1931. Voltando a sua primeira tese de habilitação, trabalho esse que fora recusado por Cornelius, o Filósofo frankfurtiano procurava encontrar as proximidades entre o inconsciente de Freud com a categoria de sujeito transcendental de Kant em que se buscava destacar ainda as "implicações cognitivas da psicanálise a qual extrai conteúdos do inconsciente para serem submetidos à análise racional” (ZUIN; PUCCI; RAMOS-DE-OLIVEIRA, 2008).

Esta concepção aparece implicitamente na Dialética do Esclarecimento, mais especificamente no capítulo "Excurso I: Ulisses e o esclarecimento", quando o Filósofo nos apresenta sua interpretação da Psicanálise, relatando como acontecera o processo do programa da civilização ocidental, exemplificando as lendárias viagens e as práticas de abnegação de Ulisses. Nesse capítulo, Adorno busca fundamentar sua "teoria psicanalista", fazendo uma análise comparativa entre a Odisseia, de Homero, e a relação intrínseca da internalização de Nietzsche e Freud. Seguindo os passos de Joel Whitebook, sobretudo de sua interpretação sobre a Dialética do Esclarecimento, Ulisses (o grande ícone da epopeia grega), por meio de sua astúcia e de seu sacrifício para os deuses, chega a um novo prisma para a razão mitológica, quer dizer, para o ordenamento de uma concepção de igual valor (teoria da equivalência do capital), representando, assim, o aparecimento de um processo de encantamento com uma troca racionalizada (WHITEBOOK, 2008).

Nesta perspectiva, cabe ressaltar que, de acordo com o prisma interpretativo de Whitebook, dos trabalhos filosóficos adornianos:

\begin{abstract}
A astúcia de Ulisses simboliza uma espécie transitória, em algum momento entre o mito e o esclarecimento, pois o ego incipiente havia se desenvolvido até o ponto a partir do qual ele podia fazer seu cálculo legal. Ele calculou que, mantendo a desordem de sua natureza interna sob o controle de um ego unificado - isto é, reprimindo sua vida inconsciente - instintiva -, poderia ludibriar a lei da equivalência e sobreviver aos inúmeros perigos que o aguardavam em sua jornada de volta para o campo casa. A tarefa principal do ego, a autopreservação, só pode ser alcançada ao manter-se no curso original. Além disso, cada ato adicional de renúncia contribui para a realidade da consolidação e da força do ego, transformando-o ainda mais num sujeito racional qua estratégico, que pode manipular o mundo externo. E na medida em que a natureza externa é reificada, esta é transformada em uma matéria apropriada de dominação (WHITEBOOK, 2008, p. 109).
\end{abstract}

A propósito, Adorno percebeu que, já nas práticas astuciosas do grande personagem da lendária Odisseia de Homero, estava inscrito o princípio do processo de esclarecimento da racionalidade ocidental. É nesse sentido que devemos compreender que, para o mesmo filósofo, tal astúcia foi o primeiro ponto para a superação do 
pensamento mitológico, chegando a ser o anímico a priori da racionalidade técnica instrumental dominadora da natureza interna e externa (ADORNO; HORKHEIMER, 1985).

Por outro lado, o filósofo alemão Julian Roberts (2008) relata que Adorno percebeu que já na Odisseia remetia a uma práxis contrária ao desejo nazista de aproximar a cultura grega, pré-helênica que tinha como uma de suas características os atos heroicos dos mitos, com aqueles que exerciam um controle totalitário sobre a economia e a natureza e, consequentemente, sobre os homens. Já com referência à Modernidade tardia, Adorno faz uma ponderação pela qual entende que o processo de individuação está constantemente ameaçado por padrões de condutas do tipo nazifascistas e de seu horror sadomasoquista que produziu a mortes de milhões de pessoas na Segunda Guerra Mundial (1939-1945), em especial nos campos de concentração. Por outro lado, "só o simples fato de citar números já é humanamente indigno, quanto mais discutir quantidades assassinadas de uma maneira mais planejada" (ADORNO, 1995, p. 120).

É nesse horizonte sombrio do capitalismo tecnicamente administrado que a esfera educacional se torna significativa, porque tem como axioma primordial evitar que esse horror barbaresco volte a se repetir. Sob esta perspectiva a Educação poderá apresentar novos caminhos para a sociedade capitalista ocidental, uma vez que vai assim de encontro às determinações falsas da aparência do "politicamente correto". Trata-se, portanto, de atribuir ao aspecto educacional uma função de resgate dos elementos críticoformativos do ser humano, isto é, forneça mecanismos para a efetivação do pensamento crítico, contribuindo para o surgimento e a manutenção de indivíduos relativamente autônomos, capazes de pensar, de julgar e de decidir por si mesmos, contrariamente a uma danificação dos sentidos e da vida (ADORNO, 1983).

A danificação focada por Adorno não se refere a nenhuma lesão ou problema mental ou biológico do homem, mas a um défice no desenvolvimento sociopsicológico dos indivíduos, que provocou a sua alienação. Em outras palavras, gerou a falta de capacidade para decidir suas ações, resultando em prejuízo para a comunidade (o coletivo). Com isso, as pessoas passaram a se comportar de modo infantilizado, não se mantendo capazes de suportar a distância temporal entre seu desejo e a satisfação deste. Assim sendo, os indivíduos passaram a buscar, a todo preço, saciar, imediatamente seus desejos, embora nunca ficassem satisfeitos por completo. Ainda no que se refere à questão educacional, cabe aqui destacar uma advertência de Adorno: não 
deve ser atribuída à Educação (especialmente à escola) a responsabilidade para solucionar as contradições do sistema capitalista, pois ela, por si só, não consegue dar conta dos problemas deste sistema socioeconômico, que, por sinal, são inúmeros. Isto porque a educação, assim como qualquer outra atividade, como o esporte, a cultura ou a arte, se desenvolve de modo entrelaçado com o conjunto infernal de atrocidades do capitalismo (ADORNO, 1995).

De acordo com Adorno, a resposta para um encaminhamento mais promissor da atividade educacional inicia-se com o descortinar dos pressupostos que dificultam a formação cultural crítica e criativa, ou melhor, de tudo aquilo que causa alguma danificação a um educar comprometido com a reflexão e autorreflexão crítica das pessoas. A propósito, o professor de Filosofia da UFSCar, Wolfgang Leo Maar (2003, p. 472), observa o seguinte a respeito da reflexão de Adorno no debate radiofônico "Educação para quê?", publicado em Educação e emancipação:

\footnotetext{
O mundo dos homens é organizado de determinada maneira e é preciso decifrar as condições e os condicionantes que causam seu modo determinado de ser. A essência não está "atrás" da aparência, mas é a reflexão da aparência acerca de seu modo de aparecer de determinado modo, o arranjo determinado do mundo, a sociedade que é sua própria ideologia. A emancipação como "conscientização" é a reflexão racional pela qual o que parece ordem natural "essencial" na sociedade cultural, decifra-se como ordem socialmente determinada em dadas condições da produção real efetiva da sociedade (MAAR, 2003, p. 472).
}

Portanto, as determinações sociais da sociedade tecnicamente administrada estão nas raízes da barbárie, ou seja, do surgimento e da reprodução de inúmeras mazelas desta sociedade. Tendo por base este entendimento, é que Adorno nos diz que o primeiro compromisso da educação e de todos que estão envolvidos com ela - pedagogos, filósofos, sociólogos, políticos, psicólogos, historiadores, entre outros profissionais; enfim, todos aqueles que, de alguma maneira deixam suas contribuições ou se utilizam do processo educacional - precisam evitar que Auschwitz, o tormento burocraticamente administrado e cientificamente planejado, volte a ocorrer (ADORNO, 1995).

Isto porque Auschwitz foi um acontecimento extremamente trágico, ou seja, foi o maior campo de concentração (e de extermínio) nazista que operou na cidade de Oswiecim, na Polônia. Aliás, esse fato passou a ser a imagem do Holocausto. Hoje, ele é o meio (simbólico) utilizado para enfatizar os aspectos traumáticos e catastróficos por excelência na Europa, entre o final da década de 1930 e o começo da década de 1940 (SELIGMANN-SILVA, 2003). 
Vale ressaltar, antes de mais nada, que esse acontecimento provocou e ainda provoca lesões graves à humanidade, porque se trata de um problema que afetou a todos e precisa ser esclarecido e solucionado socialmente. Os horrores resultaram em extermínios, exílios, torturas, perseguições, discriminações étnicas e racistas, mortes trágicas e violentas, danos materiais e imateriais e desastres econômicos e políticos. Fazse necessário esclarecer, no entanto, que os prejuízos que Auschwitz deixou não se restringem às tragédias ocorridas e às dores físicas ou psicológicas infligidas. Os danos foram muito mais além, pelo simples motivo de um elevado número de pessoas ter sido acometido pelo desprezo, pela falta de autoestima e pelo desaparecimento de sua memória ou de sua recordação. Como consequência, esse problema, por excelência, se reproduz na falta de memória - ou em um lapso de memória - para estes traumáticos processos históricos da humanidade, resultando em esquecimento dos males gerados pelas práticas patológicas do nazismo (ADORNO, 1995).

É por isso que Adorno (1995) exprime que um dos objetivos da sociedade industrial ocidental é exatamente eliminar o aspecto da memória, da lembrança e do tempo. Conforme os argumentos da sociedade capitalista europeia, esses aspectos designam significados dolorosos, que incomodam os que praticaram e/ou participaram direta ou indiretamente das atrocidades nazistas e neonazistas. E, portanto, estes aspectos precisam ser excluídos. De acordo com Adorno:

[...] Do mesmo modo como a racionalização progressiva dos procedimentos da produção industrial elimina junto aos outros restos de atividade artesanal também categorias como a da aprendizagem, ou seja, relevantes ao tempo de aquisição da experiência no ofício. Quando a humanidade se aliena da memória, esgotando-se sem fôlego na adaptação ao existente, nisto reflete-se uma lei objetiva de desenvolvimento (ADORNO, 1995, p. 33).

No debate radiofônico "Educação após Auschwitz", Adorno (1995) faz a seguinte observação, levando em conta as constelações conceituais freudianas para entender o processo civilizatório, afirmando que o Psicanalista vienense estava correto ao dizer que tal processo remeteria tão-somente ao seu oposto, a saber, aparecendo exponencialmente de modo insuportável no seio do capitalismo tardio. O Filósofo frankfurtiano acrescenta a respeito de Freud:

\footnotetext{
Juntamente no que diz respeito a Auschwitz, os seus ensaios $O$ mal-estar na cultura; Psicologia de massas e Análise do eu mereciam a mais ampla divulgação. Se a barbárie encontra-se no próprio princípio civilizatório, então pretender se opor a isso tem algo de desesperador (ADORNO, 1995, p. 120).
}

$\mathrm{Na}$ concepção de Adorno, se este problema da infindável possibilidade de recrudescimento da barbárie em meio civilizatório não for profunda e amplamente 
debatido e permanentemente tornado público, ele pode fazer recrudescer a barbárie. No que tange ao aspecto da educação, em especial na escola, deu-se pouca importância ao tratamento dessa grande barbárie, sendo que o aspecto educacional se distanciou, cada vez mais, dessa questão (ADORNO, 1995).

Por preferir tal questão, a educação se mostra como mera adequação do sujeito à "rede simbólica" petrificada e alienante, ou seja, uma ordem formal complexa e, como diria o filósofo francês Louis Althusser, amparada pelos aparelhos ideológicos de Estado - (AIE), escola, universidade, rádio, religião, imprensa e principalmente a família, uma vez que ela representa uma instância de socialização e de educação primária dos indivíduos) que, mediante suas estruturas institucionais, mistificam a realidade e o esclarecimento humano quando legitimam suas posições homogeneizantes. Para deixar esta argumentação ainda mais consistente, Adorno faz referência ao Kant da ontologia do presente, quer dizer, ao memorável artigo, de 1784, Was ist Aufklärung (O que é esclarecimento?), afirmando que os indivíduos não estão correspondendo à maioridade do pensamento. Ou seja, por estarem presos a uma situação de menoridade culpável, pelo qual se encontram presos na impossibilidade do exercício de autonomia, ficando reféns do pensamento de outrem (cultura, família, política, religião, filosofia e a ciência) (ADORNO; HORKHEIMER, 1985).

Tanto segundo a argumentação de Kant como de Adorno, grande parte dos indivíduos se encontra sob os códigos da menoridade, mas com a necessidade de esta situação ser superada. As pessoas precisam urgentemente sair da acomodação em relação ao que lhes é dado e imposto como verdadeiro, como se a reificação social fosse natural e não pudesse ser superada no horizonte de suas vidas. A propósito, de acordo com Kant:

É preciso ter a coragem de usar o seu próprio entendimento é, portanto, o motto do Esclarecimento. Preguiça e covardia são as razões de a maior parte da humanidade, de bom grado, viver como menor durante toda a sua vida, mesmo depois de a natureza há muito tempo tê-la livrado de guias externos. Preguiça e covardia demonstram porque é tão fácil para alguns se manterem como tutores (KANT, 1985, p. 101).

Nas palavras do filósofo frankfurtiano, o aspecto da educação não teve a coragem de superar a menoridade, haja vista que ela não cumpriu, por exemplo, o que, por sua vez, havia de mais significativo no plano socioeducacional: ajudar no processo de resistência e de desbarbarização da humanidade. A prova disso é a pouca consciência dos indivíduos, ou melhor, o pequeno número de pessoas informadas e realmente 
conscientes sobre as terríveis monstruosidades cometidas em Auschwitz, e isto em uma sociedade considerada esclarecida (ADORNO, 1995).

\section{Referências Bibliográficas}

ADORNO, Theodor W.; HORKHEIMER, Max. Dialética do esclarecimento: fragmentos filosóficos. Tradução de Guido Antonio de Almeida. Rio de Janeiro: Zahar Ed., 1985.

ADORNO, Theodor W. O fetichismo na música e a regressão da audição. Tradução de Luiz João Baraúna. São Paulo: Abril Cultural, 1983. (Coleção Os Pensadores).

São Paulo: Paz e Terra, 1995.

Educação e emancipação. Tradução de Wolfgang Leo Maar.

Introdução à sociologia. Tradução de Wolfgang Leo Maar. São Paulo: Ed. UNESP, 2008.

ALTHUSSER, Louis. Aparelhos ideológicos de Estado. Rio de Janeiro: Graal, 1992.

ASSOUN, Paul-Laurent. Escola de Frankfurt. São Paulo: Ática, 1991.

CESAROTTO, Oscar; LEITE, Maria Peter de Souza. O que é psicanálise? São Paulo: Brasiliense, 1987.

KANT, Immanuel. Resposta à pergunta: que é esclarecimento? (Aufklärung). In:

Textos Seletos. Petrópolis: Vozes, 1985. p.101-111.

KASTRUP, Virgínia. A invenção de si e do mundo: uma introdução do tempo e do coletivo nos estudos da cognição. São Paulo: Papirus, 1999.

LACAN, Jacques. O Seminário, livro 7: a ética da Psicanálise. Rio de Janeiro: Jorge Zahar, 1988.

MAAR, Wolfgang Leo. Adorno, semiformação e educação. Educ. Soc., Campinas, v. 24, n. 83, p. 459-476, ago. 2003. Disponível em <http://www.cedes.unicamp.br>. Acesso em: 20 jan. 2010.

À Guisa de introdução: Adorno e a experiência formativa. In:

ADORNO, Theodor. Educação e emancipação. São Paulo, Paz e Terra, 1995.

ROBERTS, Julian. A dialética do esclarecimento. In: RUSH, Fred. (Org.). Teoria crítica. Aparecida: Ideias \& Letras, 2008.

ROUANET, Sérgio Paulo. Teoria Crítica e Psicanálise. Rio de Janeiro: Tempo Brasileiro, 1989. 
RUSH, Fred (Org.). As bases conceituais da primeira teoria crítica. In:_. Teoria Crítica. Aparecida: Ideias \& Letras, 2008.

SAFATLE, Vladimir. Sobre a gênese psicológica do transcendental: Adorno entre Freud e Kant. In: SAFATLE, Vladimir; MANZI, Ronaldo (Org.). A filosofia após Freud. São Paulo: Humanitas, 2008.

Brasileira, 2010.

Freud: Fetichismo colonizar o outro. Rio de Janeiro: Civilização

SELIGMANN-SILVA, Marcio. Adorno. São Paulo: Publifolha, 2003.

WHITEBOOK, Joel. A união de Marx e Freud: a teoria crítica e a psicanálise. In:

Teoria crítica (Org.). São Paulo: Ideias e Letras, 2008.

ŽIŽEK, Slavoj. Eles não o que fazem: o sublime objeto da ideologia. Rio de Janeiro: Jorge Zahar, 1992.

. Como ler Lacan. Rio de Janeiro: Jorge Zahar Editor, 2006.

ZUIN, Antônio. PUCCI; RAMOS-DE-OLIVEIRA. Adorno: o poder educativo do pensamento crítico. Petrópolis, RJ: Vozes, 2008. 